\title{
On the True Maximum Efficiency Operations of Synchronous Motor Drives
}

\author{
F. Tinazzi*, P. Sandulescu ${ }^{\dagger}$, L. Peretti ${ }^{\dagger}$, M. Zigliotto* \\ * University of Padova, Dept. of Management and Engineering, Stradella San Nicola 6, 36100 Vicenza, Italy \\ $\dagger$ ABB Corporate Research, Dept. of Electrical Systems, Forskargränd 7, 71278 Västerås, Sweden
}

\begin{abstract}
Energy efficient AC drives for synchronous machines are key components in modern mechatronic systems, including applications of renewable energy and transportation. It is possible that the next generation of synchronous motors may be of the reluctance-prevalent type, due to the ecological footprint and cost of permanent magnet materials. When a reluctance torque is available, the torque is usually regulated according to the maximum torque per ampere principle which minimises the copper losses for a given torque request. However, iron and additional losses also contribute to the total machine losses, although their influence on the best current vector trajectory for total loss minimisation is not clear yet. The aim of this paper is to discuss and quantitatively evaluate the effect of iron and additional losses on the efficiency of different synchronous machines, looking for the true maximum efficiency. An extended batch of measurements performed on different types of machines with low power rating are discussed in detail.
\end{abstract}

\section{INTRODUCTION}

An AC drive is a complex system composed of a power unit and a control unit and several parts, such as inductors, a rectifier, DC link capacitors, an inverter and an electric machine. According to the recent international standards such as the norm EN 50598, when the rectifier and the DC link capacitors are in the same inverter case, the definition of complete drive module (CDM) is given. Another definition of power drive system (PDS) is given for the combination of the CDM and the electric machine. The standard EN 505982 defines energy efficiency indicators for the CDM and the PDS, including methodologies to determine their losses, for machines in the range $0.12 \mathrm{~kW}$ to $1000 \mathrm{~kW}$ (100 to $1000 \mathrm{~V})$. The extended product approach introduced by those standards deals with the efficiency of the PDS [1].

Following the publication of the norm, an upsurge of activities related to loss calculation appeared again in the literature. The inverter losses, actually intended as the CDM losses, are discussed in [2] and [3]. Some methods to calculate losses in permanent magnet assisted synchronous machines are discussed in [4]. The efficiency of an induction motor (IM) in several operating points was assessed in [5], [6]. An interesting approach to evaluate the energy efficiency of a synchronous reluctance (SynR) machine with a calorimetric setup is presented in [7], although no mention of the adopted torque control strategy is reported and it is not possible to isolate the mechanical losses (friction and windage).

As regards to the CDM losses, and shifting the attention on how the control algorithms affect such losses, it is known that the efficiency-oriented control techniques often neglect the total CDM losses, while focusing almost exclusively on the maximisation of the electric machine efficiency [8]. Reasons may be found in the machine losses predominance compared to the losses in the frequency converter. For instance, the efficiency of low power motors with a rating of few $\mathrm{kWs}$ may go below $90 \%$, far lower than the corresponding frequency converter efficiency in the same power range [8].

A further simplification is also typically employed by conventional control algorithms. As the copper losses can be easily modelled and estimated through the measurement of phase currents, and often they are also the dominant share of losses in the machine, the most popular torque control technique for synchronous machines is known as maximum torque-per-ampere (MTPA) control. Such strategy chooses the current control vector in such a way that the copper losses are minimised for a given torque request [9]-[11].

In general terms, the MTPA strategy may not lead to the maximum machine efficiency, as iron and additional losses are not considered in the minimisation process. However, their sum changes as function of the rotating speed and load, and the calculation of their contribution is not trivial and indisputable, since their values are often derived from the estimation of the mechanical losses. There is also some lack of knowledge on the effect of iron and additional losses from an experimental point of view. Therefore, the aim of this work is to reach a somewhat clearer and quantitative view on the benefits/disadvantages of maximum efficiency control for synchronous machines, by testing machines of different type (IPMs, SynRs) and power rating. An electric power inputoutput approach is considered for the efficiency assessment, recording the differences between the MTPA operation and the actual maximum efficiency (ME) operation. The results prove useful to draw some considerations about the loss minimisation in next-generation electric drives.

\section{THEORY OF OPERATIONS}

\section{A. Machine model}

In this paper, the focus is given to electric machines with reluctance torque components, as IPMs and SynRs. Both can be described by a similar set of equations in the reference frame $d q$ rotating with the rotor. A formulation containing a description of the iron and additional losses by means of a nonlinear parallel resistor $R_{i}$ on the stator side in the equivalent circuit of the machine [12] is reported below, and depicted in Fig. II-A for the $d$ axis only (the $q$ axis one is similar). 


$$
\begin{aligned}
u_{d} & =R_{s} i_{s d}+R_{i} i_{i d} \\
R_{i} i_{i d} & =\frac{d \lambda_{d}}{d t}-\omega_{m e} \lambda_{q} \\
u_{q} & =R_{s} i_{s q}+R_{i} i_{i q} \\
R_{i} i_{i q} & =\frac{d \lambda_{q}}{d t}+\omega_{m e} \lambda_{d} \\
i_{s d} & =i_{i d}+i_{m d} \\
i_{s q} & =i_{i q}+i_{m q} \\
\lambda_{d} & =f_{d}\left(i_{m d}, i_{m q}, \lambda_{m g}\right) \\
\lambda_{q} & =f_{q}\left(i_{m d}, i_{m q}, \lambda_{m g}\right) \\
\tau & =\frac{3}{2} p\left(\lambda_{d} i_{m q}-\lambda_{q} i_{m d}\right) \\
\omega_{m} & =J_{m} \frac{d \omega_{m}}{d t}+B_{m} \omega_{m}
\end{aligned}
$$

In this formulation, and referring to the $d q$ plane, the currents are divided in stator currents $\left(i_{s d}\right.$ and $\left.i_{s q}\right)$, iron and additional loss currents $\left(i_{i d}\right.$ and $\left.i_{i q}\right)$ and magnetising currents $\left(i_{m d}\right.$ and $\left.i_{m q}\right)$. Moreover, $u_{d}, u_{q}$ are the voltages, $\lambda_{d}, \lambda_{q}$ are the flux linkages, $R_{s}$ represents the stator resistance, $\lambda_{m g}$ is the flux linkage originated by the magnets (if present), $p$ is the pole pair number, $\tau$ is the electromechanical torque, $\omega_{m e}$ is the electromechanical speed, $\omega_{m}=\omega_{m e} / p$ is the mechanical speed, $J_{m}$ is the mechanical inertia and $B_{m}$ is the viscous friction. The non-linear relation between currents and flux linkages is described by the functions $f_{d}$ and $f_{q}$, which depend on both magnetising currents and the flux from the magnets (if present). In this way, magnetic saturation and cross-saturation can be taken into account.

It is worth noticing that the magnetising currents are a nonmeasurable quantity, since only the stator currents are available in the drive. Any attempt to draw the non-linear maps between currents and flux linkages is approximate because of the nonmeasurable nature of the magnetising currents.

\section{B. Efficiency evaluation}

Due to the complexity in estimating the parameter $R_{i}$ and the magnetising currents in Fig. II-A, this model is not used for efficiency calculation and a direct evaluation of the input electric power and output mechanical power is used instead.

As regards to the input electric power, the calculation is not performed in the $d q$ reference frame but directly in the $a b c$ stationary reference frame. Considering three phase currents,

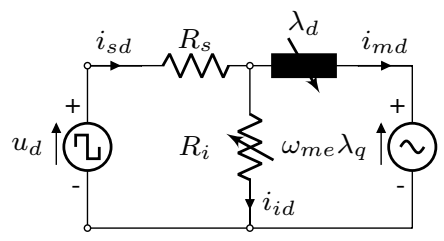

Fig. 1. The $d$-axis equivalent circuit with copper losses and iron and additional losses. the general formulation of the input electric power when the star point is not available $\left(i_{a}+i_{b}+i_{c}=0\right)$ is:

$$
P_{e l}=v_{a c} i_{a}+v_{b c} i_{b}
$$

where $v_{a c}$ and $v_{b c}$ are the actual phase-to-phase voltages between the $a$ phase and the $c$ phase, and between the $b$ phase and the $c$ respectively. The advantage of (11) is that only electric measurements are used without any transformation.

The output power is instead calculated by measuring the rotating speed and the torque:

$$
P_{m}=\omega_{m} \tau_{m}
$$

where the speed $\omega_{m}$ and shaft torque $\tau_{m}$ are measured by means of a position sensor and torquemeter, respectively.

The efficiency assessment is carried out by means of the input-output method recommended in the standards for synchronous machines [13]. The efficiency $\eta$ of the motor is equal to:

$$
\eta=\frac{P_{m}}{P_{1}}
$$

with

$$
P_{1}=\frac{1}{t_{2}-t_{1}} \int_{t_{1}}^{t_{2}} P_{e l} d t
$$

where the time $t_{2}-t_{1}$ should be selected as a multiple of the complete revolution period of the motor. In mathematical terms, $t_{2}-t_{1}=N_{r} 60 /\left(\Omega_{N} x_{\%}\right)$ where $\Omega_{N}$ is the nominal speed of the motor in rpm and $x_{\%}$ is the percentage of the nominal speed considered at each test.

On one hand, the time length $t_{2}-t_{1}$ should be kept as low as possible, in order to keep the stator resistance variation as function of the temperature at minimum. On the other hand, it should be long enough to minimise the influence of measurement uncertainties. A design compromise was reached by adopting $N_{r}=15$. The (14) can be rewritten as follows:

$$
P_{1}=\frac{\Omega_{N} x_{\%}}{N_{r} 60} \int_{0}^{\frac{\Omega_{N} x_{\%}}{N_{r} 60}} P_{e l} d t .
$$

The accuracy of the efficiency assessment relates to the accuracy of the measured variables involved in the (11)-(14). This part will be discussed in more detail in Sect. III.

\section{Test rig and experiment design}

A schematic of the experimental test rig is reported in Fig. 2. The mechanical speed and the currents of the machine under test (MUT) are regulated, while a second machine connected in back-to-back provides the required load level.

The current control loop in the $d q$ reference frame adopts the angle definitions of Fig. 3. In particular, the angle $\gamma$ defines the phase of the current space vector in the $d q$ reference frame.

The measurements are gathered at different speeds and loads according to the test points of Fig. 4a. A total of nine operating points was recorded during the experimental tests, namely at $25 \%, 50 \%$ and $75 \%$ of both nominal speed and nominal torque, according to the region sketched in Fig. $4 a$. 


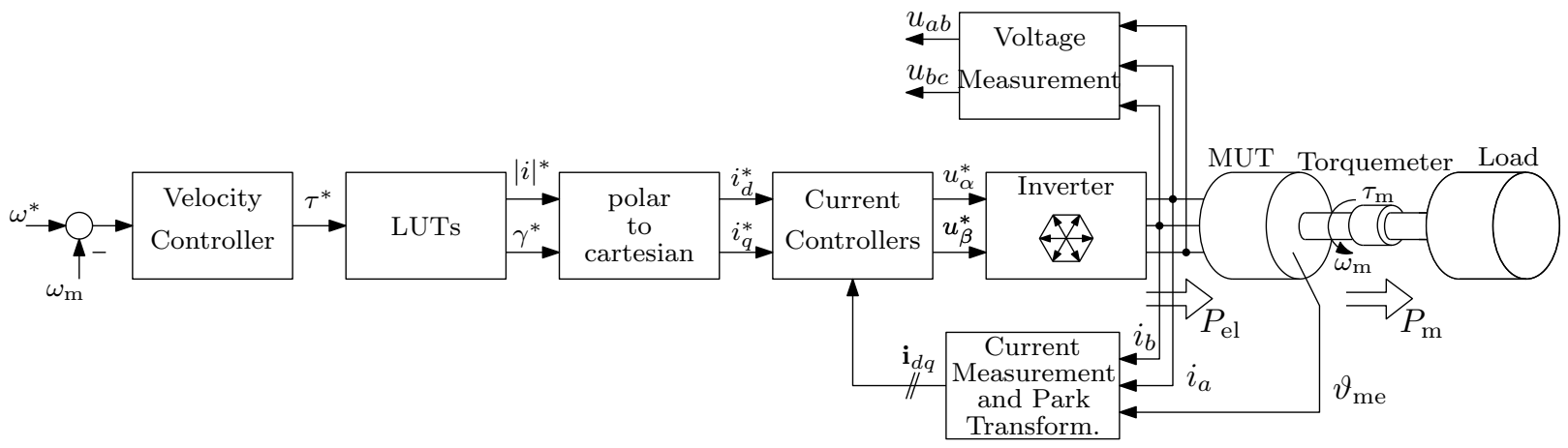

Fig. 2. Schematic of the electric drive test bench with measurement for the energy efficiency assessment.
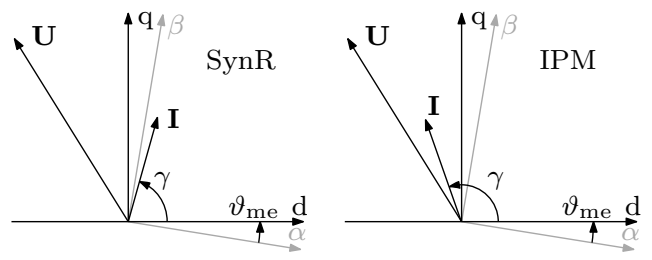

Fig. 3. Angle definitions for the current vector in SynRs and IPMs.


Fig. 4. (a) operative region test points, and (b) current vector phase change at speed steady state for the SynR case.

For each operating point, the drive is first operated in MTPA control, where the torque reference $\tau^{*}$ is sent to look-up tables (LUTs in Fig. 2) which deliver the magnitude $|i|^{*}$ and phase $\gamma^{*}$ of the reference current vector in polar coordinates, according to a pre-calculated map.

In order to evaluate the efficiency around the given MTPA point, the LUT generating the current reference phase $\gamma^{*}$ is modified as as reported in Fig. 5. For each operating point, the

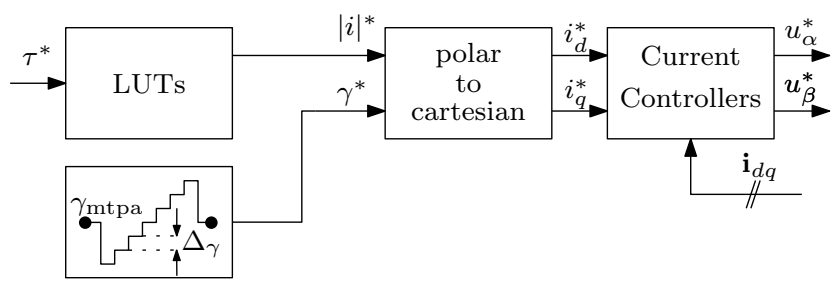

Fig. 5. Proposed LUT modification current reference phase is changed in a staircase fashion with a variation equal to $\Delta_{\gamma}$. Being forced to keep a constant speed by the outer speed regulator, the drive continues to deliver the requested load torque, but the modification of $\gamma^{*}$ into a non-MTPA value forces the speed regulator to artificially change the torque reference (which thus mismatches the actual delivered torque) to increase the reference magnitude $|i|^{*}$. This situation is depicted in Fig. 4b. The overall outcome is that the machine under test works in the same mechanical operating point but in a different electrical operating point, making it possible to record the efficiency differences for different choices of current magnitude and phase.

Two parameters must be set for the modification of Fig. 5, which are the number of steps $N_{s}$ of the reference phase $\gamma^{*}$ and the phase variation between two consecutive steps $\Delta_{\gamma}$. In this work, the value of $N_{s}$ was set to 11 . As regards to $\Delta_{\gamma}$, its value can be decided as certain variation of $\pm \Delta_{\gamma} / 2$ around the MTPA operating point. As rule of thumb, $\Delta_{\gamma}$ can be chosen between the range $2 \div 5$.

\section{MACHINES UNDER TEST AND MEASUREMENT UNCERTAINTIES}

The nameplate data of the machines under test is reported in Table I. Different sets of sensors were used for the machines, and thus different accuracy in the tests are obtained.

The mechanical torque is measured by means of a torquemeter. The $\mathrm{SynR}_{1}$ torque was measured by means of a Magtrol TM308, capable of measuring torques with a range between 0.1 and $20 \mathrm{Nm}$ and a declared accuracy $<0.1 \%$ of the rated torque. The $\mathrm{SynR}_{2}$ and the $\mathrm{IPM}_{1}$ torque was measured with a Magtrol TM311, measuring up to $100 \mathrm{Nm}$ with the same accuracy class of $<0.1 \%$ of the rated torque.

TABLE I

NAMEPLATE DATA OF THE MOTORS UNDER TEST.

\begin{tabular}{lccc}
\hline Parameters & SynR $_{1}$ & SynR $_{2}$ & $\mathrm{IPM}_{1}$ \\
\hline Power $P_{\mathrm{N}}$ & $1.6 \mathrm{~kW}$ & $5.5 \mathrm{~kW}$ & $15 \mathrm{~kW}$ \\
Speed $\Omega_{\mathrm{N}}$ & $1500 \mathrm{rpm}$ & $3000 \mathrm{rpm}$ & $1800 \mathrm{rpm}$ \\
Current $I_{\mathrm{N}}$ & $8.6 \mathrm{~A}$ & $13.4 \mathrm{~A}$ & $21.2 \mathrm{~A}$ \\
\hline
\end{tabular}


The speed measurement accuracy is related to the position sensor resolution and the method used to calculate the speed. A 14-bit resolver was adopted for the $S_{y n R}$, with the speed calculated as derivative of the position every $2.5 \mathrm{~ms}$. A 16-bit resolver was adopted for the $S_{2 y n}$ and $\mathrm{IPM}_{1}$, with the speed calculated in the same way every $250 \mu \mathrm{s}$. According to [14], this leads to a relative accuracy of $15.34 / \omega_{m} \%$ for the $S_{y n R}$, and of $38 / \omega_{m} \%$ for the $\mathrm{SynR}_{2}$ and $\mathrm{IPM}_{1}$.

The LEM 25-NP current sensor was used for the $\mathrm{SynR}_{1}$. The expanded uncertainty of the current measurement chain is estimated at $0.125 \mathrm{~A}$, i.e. the $0.5 \%$ respect to the nominal value of $25 \mathrm{~A}$. The $\mathrm{SynR}_{2}$ and the $\mathrm{IPM}_{1}$, instead, were measured with LEM LA 55-P/SP1 components, with an extended accuracy of $0.325 \mathrm{~A}(0.65 \%$ of the nominal current $50 \mathrm{~A})$.

The voltage measurements for the $S_{y n R}$ were carried out by means of a dedicated board based on high sampling frequency $(1 \mathrm{MHz})$ and FPGA [15]. The expanded uncertainty of the measurement equipment is estimated at $11.7 \cdot 10^{-3} U_{\mathrm{dc}}$. Such figure accounts for all the uncertainties of the electronic components, sampling and analog-to-digital conversion. The $\mathrm{SynR}_{2}$ and IPM2 voltages, instead, were measured with LEM voltage transducers CV 3-1500, with an accuracy of $0.2 \%$ of the maximum allowed voltage $(1500 \mathrm{~V})$, translating into an expanded uncertainty of $3 \mathrm{~V}$.

\section{EXPERIMENTAL RESULTS AND DISCUSSION}

The experimental results for the machines in Table I are shown in Fig. $6\left(\mathrm{SynR}_{1}\right)$, Fig. $7\left(\mathrm{SynR}_{2}\right)$ and Fig. $8\left(\mathrm{IPM}_{1}\right)$. In all test cases, the results suggest that the MTPA operating point is not the point where the maximum efficiency of the machine is achieved. Morevoer, a different behaviour is found among the SynR cases and the IPM case. In both SynR tests, the maximum efficiency is found when the current angle $\gamma$ is always slightly increased with respect to the MTPA one. According to the definitions of Fig. 3, this means that the maximum efficiency is obtained when the $d$-axis current is slightly decreased and the $q$-axis current is increased. In other terms, the machines (working in the first quadrant with positive speed and positive torque) are slightly flux-weakened.

A possible reason to this behaviour is shown in Fig. 9, where further measurements were performed at $80 \%$ of the nominal speed and at $25 \%$ of the nominal load (for the sake of completeness and comparison with Fig. 6, Fig. 9b reports also the efficiency for $50 \%$ and $75 \%$ of the nominal load). In particular, Fig. 9c shows that while the copper losses are increasing for increased $\gamma$ angles, the iron losses decrease and stabilise for the same $\gamma$ values. The sum of copper and iron losses is therefore minimum in an operating point which differs slightly from the MTPA one. This is in line with the expected dependence of iron losses on the magnitude of the air-gap field [16]. Table II and Table III summarise the fundamental voltage and current values for the $\mathrm{SynR}_{1}$ and $\mathrm{SynR}_{2}$ tests. The ME point is the one with a lower voltage magnitude, as expected in flux weakening.

As regards to the $\mathrm{IPM}_{1}$ measurements, it is interesting to observe that for low speeds the maximum efficiency point is reached when some degree of flux weakening is applied (i.e. increasing the magnitude of the $d$-axis current in the negative direction), while for higher speeds the maximum efficiency point is found with a slight increase of flux linkage in the machine (by decreasing the magnitude of the $d$-axis current). This is further documented in Table IV. This may be caused by the increased contribution of magnet eddy current losses at higher speed, which may be sensitive to a higher magnitude of the $d$-axis current due to increased flux densities travelling across the permanent magnets [17].

\section{A. Energy consumption calculation}

The experimental results have been further processed to quantify the energy consumption in a hypothetical process composed by different load requirements over a typical machine lifetime. Some assumptions were made. The torquespeed law of the process is quadratic, representing for example centrifugal pumps and fans [18]. The different load requirements are calculated for a speed range between $30 \%$ and $100 \%$ of the nominal speed, and by considering a distribution of operating hours following a bell curve starting at $5 \%$ of the total hours at $30 \%$ of the nominal speed, increasing by $5 \%$ to $20 \%$ at $60 \%$ of the nominal speed, and then lowering symmetrically to reach the nominal speed. The lifetime of the machines has been set to 20 years, and the total number of operating hours per year is set to 6000 hours.

The energy consumption results are shown in Table V. In all cases, the energy saving by running in the ME point is present but fairly small. This result, however, is not surprising because the power rating of the machines is quite low - it is possible that in machines with larger power the contribution of the iron and additional losses is more significant, thus potentially reaching larger energy savings in ME mode.

\section{CONCLUSIONS AND FUTURE WORK}

This paper discusses the issue of maximum efficiency operation in synchronous machines, howing that the maximumtorque-per-ampere trajectory does not ensure minimal loss operation and that some energy savings could be achieved if maximum efficiency control is used instead. The savings seem to be rather small, but this may relate to the small power range of the three machines under test.

Future works may include similar measurements on machines with higher power ratings, and loss measurements at the rectifier input stage of a conventional drive, in order to include the drive losses into the evaluation.

\section{REFERENCES}

[1] I. P. Tsoumas, H. Tischmacher, and P. Köllensperger, "The european standard en 50598-2: Efficiency classes of converters and drive systems,' Proceedings of the 2014 International Conference on Electrical Machines (ICEM), Berlin, Germany, Sep.2-5 2014, pp. 929-935. [Online]. Available: https://doi.org/10.1109/ICELMACH.2014.6960292

[2] F. W. Fuchs, J. Schrder, and B. Wittig, "State of the technology of power loss determination in power converters," in 2013 15th European Conference on Power Electronics and Applications (EPE), Sept 2013, pp. $1-10$. 
TABLE II

FUNDAMENTAL VOLTAGE AND CURRENT MAGNITUDES FOR THE SYNR 1 TESTS.

\begin{tabular}{|c|c|c|c|c|c|c|c|c|c|c|c|c|}
\cline { 2 - 13 } \multicolumn{1}{c|}{} & \multicolumn{4}{c|}{$25 \% \omega_{N}$} & \multicolumn{4}{c|}{$50 \% \omega_{N}$} & \multicolumn{4}{c|}{$75 \% \omega_{N}$} \\
\cline { 2 - 13 } \multicolumn{1}{c|}{} & \multicolumn{4}{c|}{ Voltage [V] } & \multicolumn{2}{c|}{ Current [A] } & \multicolumn{2}{c|}{ Voltage [V] } & \multicolumn{2}{c|}{ Current [A] } & \multicolumn{3}{c|}{ Voltage [V] } & \multicolumn{2}{c|}{ Current [A] } \\
\cline { 2 - 13 } \multicolumn{1}{c|}{} & MTPA & ME & MTPA & ME & MTPA & ME & MTPA & ME & MTPA A & ME & MTPA & ME \\
\hline $25 \% \tau_{N}$ & 55.53 & 46.03 & 2.15 & 2.23 & 104.22 & 94.53 & 2.17 & 2.20 & 150.32 & 134.52 & 2.20 & 2.24 \\
\hline $50 \% \tau_{N}$ & 90.12 & 89.09 & 4.78 & 4.78 & 166.93 & 162.20 & 4.81 & 4.82 & 240.17 & 229.65 & 4.75 & 4.79 \\
\hline $75 \% \tau_{N}$ & 103.9 & 103.7 & 6.49 & 6.49 & 188.33 & 183.10 & 6.52 & 6.54 & 270.10 & 269.44 & 6.54 & 6.54 \\
\hline
\end{tabular}

TABLE III

FUNDAMENTAL VOLTAGE AND CURRENT MAGNITUDES FOR THE SYNR 2 TESTS.

\begin{tabular}{|c|c|c|c|c|c|c|c|c|c|c|c|c|}
\cline { 2 - 13 } & \multicolumn{4}{|c|}{$25 \% \omega_{N}$} & \multicolumn{4}{c|}{$50 \% \omega_{N}$} & \multicolumn{4}{c|}{$75 \% \omega_{N}$} \\
\cline { 2 - 14 } & \multicolumn{1}{|c|}{ Voltage [V] } & \multicolumn{2}{c|}{ Current [A] } & \multicolumn{2}{c|}{ Voltage [V] } & \multicolumn{2}{c|}{ Current [A] } & \multicolumn{3}{c|}{ Voltage [V] } & \multicolumn{2}{c|}{ Current [A] } \\
\cline { 2 - 13 } & MTPA & ME & MTPA & ME & MTPA & ME & MTPA & ME & MTPA & ME & MTPA & ME \\
\hline $25 \% \tau_{N}$ & 57.99 & 54.33 & 7.37 & 7.43 & 112.03 & 87.12 & 7.37 & 8.16 & 167.84 & 133.63 & 7.31 & 7.68 \\
\hline $50 \% \tau_{N}$ & 73.17 & 71.81 & 11.04 & 11.05 & 139.20 & 138.26 & 11.02 & 11.02 & 206.72 & 198.19 & 10.98 & 11.04 \\
\hline $75 \% \tau_{N}$ & 80.99 & 80.50 & 14.11 & 14.12 & 153.65 & 156.92 & 14.36 & 14.38 & 225.09 & 221.48 & 14.16 & 14.18 \\
\hline
\end{tabular}

TABLE IV

FUNDAMENTAL VOLTAGE AND CURRENT MAGNITUDES FOR THE IPM 1 TESTS.

\begin{tabular}{|c|c|c|c|c|c|c|c|c|c|c|c|c|}
\cline { 2 - 13 } \multicolumn{1}{c|}{} & \multicolumn{4}{c|}{$25 \% \omega_{N}$} & \multicolumn{4}{c|}{$50 \% \omega_{N}$} & \multicolumn{4}{c|}{$75 \% \omega_{N}$} \\
\cline { 2 - 14 } \multicolumn{1}{c|}{} & \multicolumn{2}{c|}{ Voltage [V] } & \multicolumn{2}{c|}{ Current [A] } & \multicolumn{2}{c|}{ Voltage [V] } & \multicolumn{2}{c|}{ Current [A] } & \multicolumn{3}{c|}{ Voltage [V] } & \multicolumn{2}{c|}{ Current [A] } \\
\cline { 2 - 13 } \multicolumn{1}{c|}{} & MTPA & ME & MTPA & ME & MTPA & ME & MTPA & ME & MTPA & ME & MTPA & ME \\
\hline $25 \% \tau_{N}$ & 72.64 & 71.01 & 9.06 & 9.10 & 142.30 & 141.11 & 8.98 & 8.99 & 212.57 & 220.29 & 9.06 & 9.16 \\
\hline $50 \% \tau_{N}$ & 83.50 & 82.44 & 16.40 & 16.43 & 162.37 & 163.87 & 16.42 & 16.43 & 241.38 & 245.79 & 16.42 & 16.45 \\
\hline $75 \% \tau_{N}$ & 90.76 & 90.14 & 23.38 & 23.35 & 175.44 & 175.44 & 23.37 & 23.37 & 260.83 & 265.07 & 23.68 & 23.74 \\
\hline
\end{tabular}

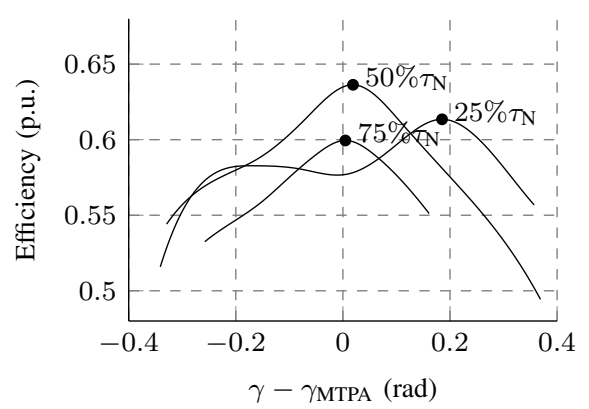

(a)

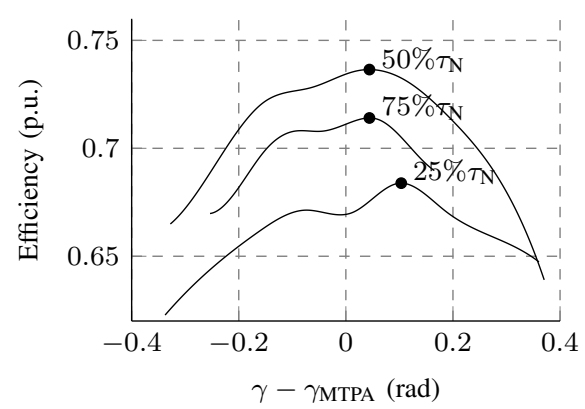

(b)

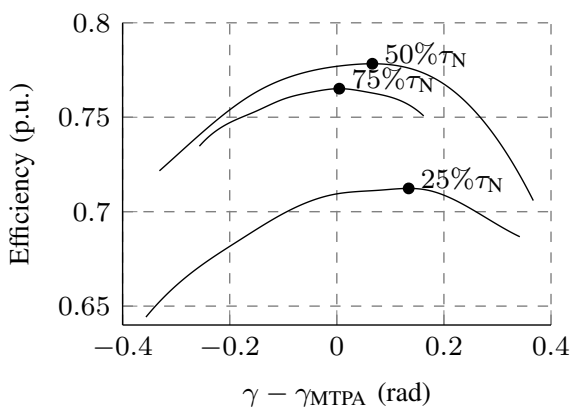

(c)

Fig. 6. Efficiency measurements on $\mathrm{SynR}_{1}$ at different loads and speeds $\left(25 \%, 50 \%\right.$ and $75 \%$ of $\Omega_{\mathrm{N}}$, from left to right).


Fig. 7. Efficiency measurements on the motor under test $S_{y n R}$ at different loads and speeds $\left(25 \%, 50 \%\right.$ and $75 \%$ of $\Omega_{\mathrm{N}}$, from left to right). 

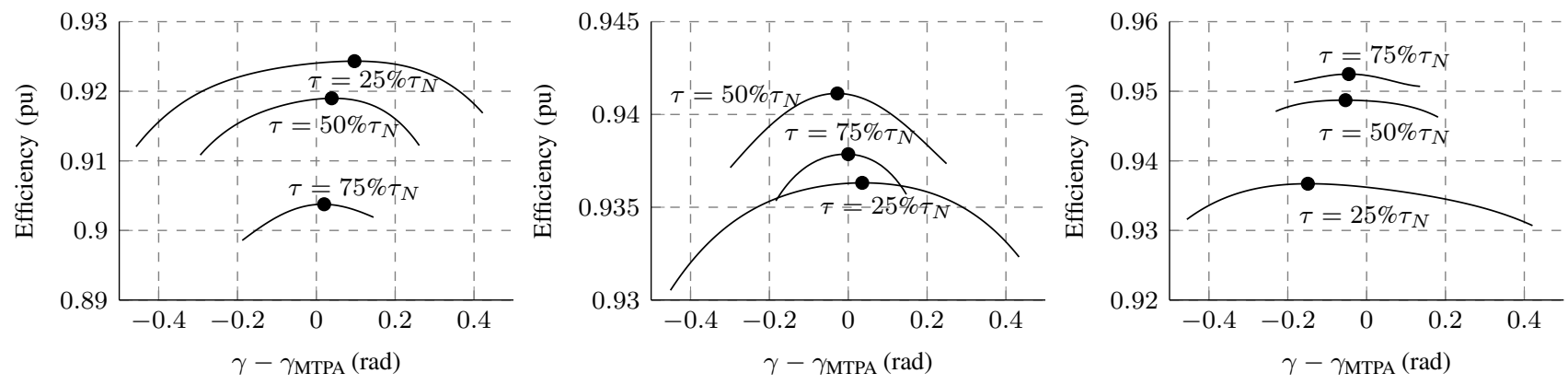

Fig. 8. Efficiency measurements on the motor under test $\mathrm{IPM}_{1}$ at different loads and speeds $\left(25 \%, 50 \%\right.$ and $75 \%$ of $\Omega_{\mathrm{N}}$, from left to right).

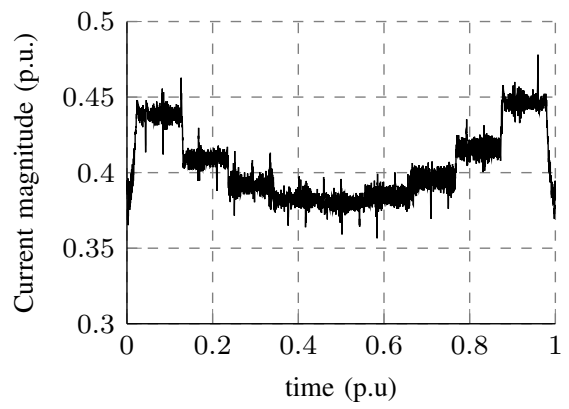

(a) Current magnitude at different $\gamma^{*}$

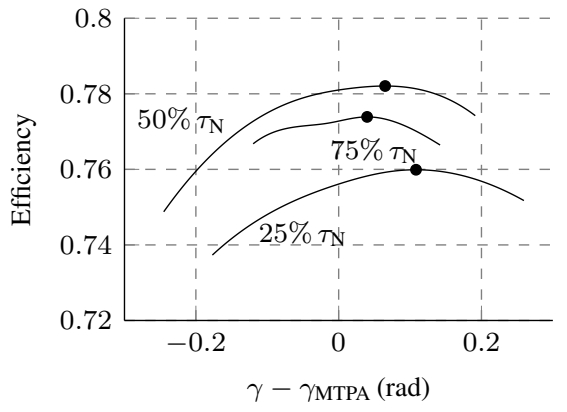

(b) Efficiency at $80 \% \Omega_{\mathrm{N}}$

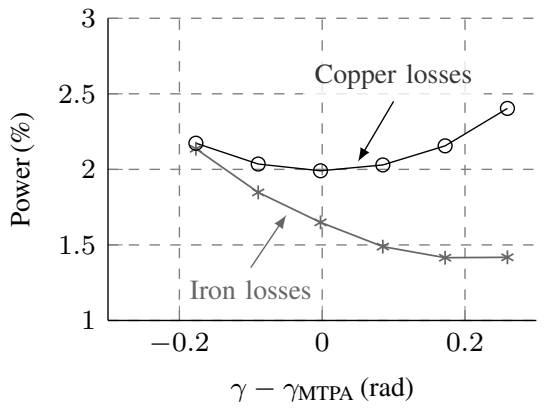

(c) Losses at $80 \% \Omega_{\mathrm{N}}$ and $25 \% \tau_{\mathrm{N}}$

Fig. 9. Further measurements on the motor under test $\mathrm{SynR}_{1}$. The power quantities are normalised to the motor nominal power.

TABLE V

MACHINES ENERGY CONSUMPTION IN MW h FOR A FICTITIOUS PROCESS.

\begin{tabular}{|c|c|c|c|}
\cline { 2 - 4 } \multicolumn{1}{c|}{} & MTPA & ME & Difference \% \\
\hline SynR $_{1}$ & 84.88 & 84.63 & 0.39 \\
\hline SynR $_{2}$ & 249.26 & 248.51 & 0.33 \\
\hline IPM $_{1}$ & 637.67 & 637.50 & 0.02 \\
\hline
\end{tabular}

[3] L. Aarniovuori, T. Musikka, A. Kosonen, M. Niemel, and J. Pyrhönen, "Three alternative methods to determine voltage source converter losses," in EPE'15 ECCE-Europe, Sept 2015, pp. 1-10.

[4] S. Melentjev, A. Belahcen, A. Kallaste, A. Rasslkin, and T. Vaimann, "Review of loss calculation reduction control methods of permanent magnet assisted reluctance drive," in 2016 Electric Power Quality and Supply Reliability (PQ), Aug 2016, pp. 199-206.

[5] H. Kärkkäinen, L. Aarniovuori, M. Niemelä, and J. Pyrhönen, "Converter-fed induction motor losses in different operating points," in EPE'16 ECCE Europe, Sept 2016, pp. 1-8.

[6] R. Antonello, F. Tinazzi, and M. Zigliotto, "Energy efficiency measurements in im: The non-trivial application of the norm iec 600342-3:2013," in 2015 IEEE WEMDCD, March 2015, pp. 248-253.

[7] L. Aarniovuori, J. Kolehmainen, A. Kosonen, M. Niemel, H. Chen, W. Cao, and J. Pyrhönen, "Application of calorimetric method for loss measurement of a SynRM drive system," IEEE Trans. Ind. Electron., vol. 63, no. 4, pp. 2005-2015, April 2016.

[8] F. Abrahamsen, F. Blaabjerg, J. K. Pedersen, and P. B. Thoegersen, "Efficiency-optimized control of medium-size induction motor drives," vol. 37, no. 6, pp. 1761-1767, Nov 2001.

[9] R. Antonello, M. Carraro, and M. Zigliotto, "Maximum-torque-perampere operation of anisotropic synchronous permanent-magnet motors based on extremum seeking control,' IEEE Trans. Ind. Electron., vol. 61, no. 9, pp. 5086-5093, Sept 2014.

[10] S. Calligaro, C. Olsen, R. Petrella, and N. Bedetti, "Automatic MTPA tracking in IPMSM drives: loop dynamics, design and auto-tuning," in 2016 IEEE Energy Conversion Congress and Exposition (ECCE), Sept 2016, pp. 1-8.

[11] S. Bolognani, L. Peretti, and M. Zigliotto, "Online MTPA Control Strategy for DTC Synchronous-Reluctance-Motor Drives," IEEE Trans. Power Electron., vol. 26, no. 1, pp. 20-28, Mar. 2011. [Online]. Available: https://doi.org/10.1109/TPEL.2010.2050493

[12] L. Peretti, P. Sandulescu, and G. Zanuso, "Self-commissioning of flux-linkage curves of synchronous reluctance machines in quasistandstill condition,' IET Electric Power Applications, vol. 9, no. 9, pp. 642-651, Nov. 2015. [Online]. Available: https://doi.org/10.1049/ietepa.2015.0070

[13] Rotating electrical machines - Part 2-1: Standard methods for determining losses and efficiency from tests (excluding machines for traction vehicles), IEC-TS Std. 60 034-2-1:2014, Sep. 2014.

[14] R. Petrella, M. Tursini, L. Peretti, and M. Zigliotto, "Speed measurement algorithms for low-resolution incremental encoder equipped drives: a comparative analysis," in 2007 International Aegean Conference on Electrical Machines and Power Electronics, Sept 2007, pp. 780-787.

[15] R. Antonello, F. Tinazzi, and M. Zigliotto, "Benefits of direct phase voltage measurement in the rotor initial position detection for permanentmagnet motor drives," IEEE Trans. Ind. Electron., vol. 62, no. 11, pp. 6719-6726, Nov 2015.

[16] D. Kowal, P. Sergeant, L. Dupr, and L. Vandenbossche, "Comparison of iron loss models for electrical machines with different frequency domain and time domain methods for excess loss prediction," IEEE Trans. Magn., vol. 51, no. 1, Jan. 2015. [Online]. Available: https://doi.org/10.1109/TMAG.2014.2338836

[17] A. Tessarolo, "A survey of state-of-the-art methods to compute rotor eddy-current losses in synchronous permanent magnet machines," in 2017 IEEE WEMDCD, Nottingham, United Kingdom, Apr. 20-21 2017. [Online]. Available: https://doi.org/10.1109/WEMDCD.2017.7947717

[18] Technical guide book, ABB Drives, Sep. 2014, doc. n. 3 AFE64514482 REV H. 